\section{Tropical Journal of Pathology and \\ Microbiology}

2021 Volume 7 Number 1 January-February

\title{
Clinic Pathological Evaluation of Benign Breasts Lesion
}

\author{
Muljibhai Chaudhari B. ${ }^{1}$, N Madiya A. ${ }^{2 *}$ \\ DOI: https://doi.org/10.17511/jopm.2021.i01.06
}

${ }^{1}$ Bharat Muljibhai Chaudhari, Assistant Professor, Department of Pathology, Banas Medical College, Palanpur, Gujarat, India.

2* Ashish N Madiya, Assistant Professor, Department of Pathology, Government Medical College, Baroda, Gujarat, India.

Introduction: Benign breast lesions are more common than malignant tumours. Hence recognizing them is important from the viewpoints of therapy and prognosis. Methodology: The materials for the study comprised of resected specimens of breast lesions received in the pathology department Karnataka Institute of Medical Sciences, Hubballi from May 2010 to April 2015. Results: A total of 600 cases of benign breast lesions were recorded. Fibroadenoma was the commonest benign breast lesions comprising $70.82 \%$, followed by fibrocystic disease $12 \%$, benign phyllodes tumour $8.3 \%$. The majority of benign breast lesions occurred in the 2 nd decade and 3 rd decade. Conclusion: Benign breast lesions were common. Conclusion: The most frequently encountered breast lesions were fibroadenomas. So recognizing them is important for therapy and prognosis.

Keywords: Benign breast lesions, fibroadenoma, gynecomastia

Corresponding Author

Ashish N Madiya, Assistant Professor, Department of Pathology, Government Medical College, Baroda, Gujarat, India.

Email: researchguide86@gmail.com
How to Cite this Article

To Browse
Chaudhari BM, Madiya AN. Clinic Pathological Evaluation of Benign Breasts Lesion. Trop J Pathol Microbiol. $2021 ; 7(1): 40-43$.

Available From

https://pathology.medresearch.in/index.php/jopm/ar ticle/view/515

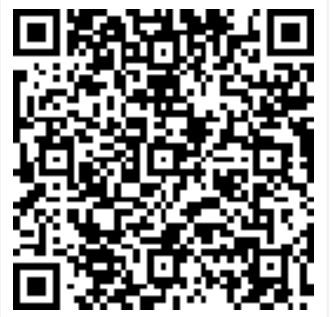

Manuscript Received 2021-01-27

Conflict of Interest No
Review Round 1 2021-01-07

Funding $\mathrm{Nil}$
Review Round 2 2021-02-17

Ethical Approval Yes
Review Round 3

Plagiarism X-checker $5 \%$
Accepted 2021-02-27

Note

(c) 2021 by Bharat Muljibhai Chaudhari, Ashish N Madiya and Published by Siddharth Health Research and Social Welfare Society. This is an Open Access article licensed under a Creative Commons Attribution 4.0 International License https://creativecommons.org/licenses/by/4.0/ unported [CC BY 4.0]. 


\section{Introduction}

Cancer of the breast has emerged as the leading site of cancer in most urban populations. It has rapidly replaced the cancer cervix as the most common cancer in women in India. Benign breast lesions encompass a wide range of lesions including inflammatory, neoplastic and aberrant hormonal response disorders [1]. Increasing awareness of breast cancer has stimulated profound interest in benign breast lesions since certain epithelial benign breast diseases have been associated with malignant transformation. Breast lesions are heterogeneous diseases that consist of several distinct entities with remarkably different characteristic features. Most of the breast lesions are well understood and well diagnosed while some of the unusual lesions and malignancies are less appreciated $[2,3]$.

The vast majority of the lesions that occur in the breast are benign. Much concern is given to malignant lesions of the breast because breast cancer is the most common malignancy in women in Western countries; however benign lesions of the breast are more frequent than malignant ones. The term "benign breast diseases" encompasses a heterogeneous group of lesions that may present a wide range of symptoms or may be detected as incidental microscopic findings $[4,5]$.

The incidences of benign breast lesions begin to rise during the second decade of life and peaks in the fourth and fifth decades, as opposed to malignant diseases, for which the incidence continues to increase after menopause, although at a less rapid pace. For many years, the relationship of benign breast disease to the risk for subsequent carcinoma was controversial $[6,7]$.

Of the several reasons for the controversy, the most important was past inconsistencies in defining benign breast diseases, not only in the field of pathology but also in radiological and clinical practice. The present study is undertaken to study the spectrum of histopathology of benign breast lesions.

\section{Materials \& Method}

The present study is a retrospective study was done or a period of 2 years. The study was done to study the histopathological study of benign breast lesions; conducted in the department of pathology in the medical college for 5 years.
A total of 300 breast tissue masses were studied, retrospective cases were studied from departmental data. Slides and blocks were retrieved and studied. The specimens received were subjected to detailed gross examination. They were initially fixed in $10 \%$ formalin, and routinely processed to obtain 5 to 6micron thick paraffin sections. Hematoxylin and eosin stain was routinely employed. All the cases were subjected to detailed microscopic examination for the features mentioned in the proforma. Inclusion criteria: All histologically proved benign breast lesion and inflammatory breast lesions. Exclusion criteria: All malignant lesions of breast and breast biopsies that did not show ductal or lobular elements were excluded.

\section{Results}

There were 600 cases of breast Benign lesions included fibroadenoma, fibrocystic disease, benign phyllodes tumour, chronic mastitis, granulomatous mastitis, gynecomastia, breast abscess, intraductal papilloma, sclerosing adenosis, tubular adenoma, mammary duct ectasia, galactocele and lactating adenoma.

Fibroadenoma was the commonest benign breast lesions comprising $70.82 \%$, followed by fibrocystic disease $12 \%$, benign phyllodes tumour $8.3 \%$ as shown in table no. 1. About $77.23 \%$ of fibroadenoma were seen in the second and third decade of life, and $82.41 \%$ of fibrocystic disease were seen in the third, fourth and fifth decade of life, $72 \%$ of benign phyllodes were seen in the third, fourth and fifth decade, $72.32 \%$ of chronic mastitis were seen in the second and third decade. Fibroadenomas occurred over a wide age range. The youngest patient was 15 years old and the oldest was 55 years old. The mean age of occurrence of fibroadenoma was 28.3 years. The majority of fibroadenoma were unilateral $(93.27 \%)$ and the rest were bilateral $(6.73 \%)$. The majority of patients showed pericanalicular followed by intracanalicular and mixed architecture.

Among 600 cases of benign breast lesions 72 cases of fibrocystic disease were encountered, which accounted for $12 \%$ of all benign breast lesions. The youngest patient was 18 years old and the oldest was 67 years old. Most cases of fibrocystic disease occurred in the 3rd and 4th decade of life. There were 52 cases of non-proliferative FCD with a mean age range of 39 years, and 20 cases of proliferative FCD without atypia with a mean age range of 35.9 years. 
There were no cases of proliferative FCD with atypia. Forty cases showed dense inflammation around ducts and lobules, 14 cases showed apocrine change and 18 cases showed fibrosis. Among 18 cases of proliferative FCD without atypia, 14 cases showed intraductal papilloma and 4 cases showed moderate ductal hyperplasia.

Out of 600 cases of benign breast lesions, 50 cases of benign phyllodes tumour were encountered which accounted for $8.30 \%$ of all benign breast lesions. The present study showed a wide age range from 16 years to 75 years old. The majority of patients were in the 4th decade followed by the 3rd and 5th decade of life. A total of 28 cases showed grade $2+$ cellularity and 22 cases showed grade $1+$ cellularity. About 46 cases showed fibroblastic stroma, 12 of them showed partly myxoid component and 4 cases showed myxoid stroma. No mixed mesenchymal elements were detected in the present study. Ten cases showed haemorrhage, 4 cases showed cysts, 4 cases showed squamous metaplasia.

Twenty-six cases $(2.05 \%)$ of chronic mastitis were encountered out of 600 cases of benign breast lesions. Chronic mastitis occurred over a wide age range. The youngest patient was 18 years old and the oldest was 58 years old. The majority of patients were in the third decade of life. Microscopy specimen shows lobules and intralobular space infiltrated with neutrophils, plasma cells; lymphocytes with foreign body giant cells were seen. Two cases showed a lactational change.

Twenty four cases of granulomatous mastitis were encountered out of 600 cases of benign breast lesions with a mean age range of 34 years. Granulomatous mastitis occurred over a wide age range. The youngest patient was 21 years old and the oldest was 51 years old with the majority of cases in the 3rd decade of life. Microscopy shows granulomas composed of epithelioid histiocytes, giant cells accompanied by lymphocytes, plasma cells, and occasional eosinophils were found within and around lobules. All cases were negative for acid-fast bacilli. Four cases showed lactational change.

Among 600 cases of benign breast lesions 22 cases of gynecomastia were encountered, which accounted for $3.6 \%$ of all benign breast lesions. The youngest patient was an 18-year-old male and the oldest was 58 years old with a mean age of 24 years with the majority of patients in the 2nd decade of life.
Twenty cases were unilateral and 2 cases had bilateral lesions. Microscopy shows ducts showed epithelial and myoepithelial cells. There was a proliferation of loose connective tissue around ductal structures. No lobule formation was seen.

Among 600 cases of benign breast lesions, 18 cases of acute mastitis were encountered which accounted for $3 \%$ of all benign breast lesions. The youngest patient was 19 years old and the oldest was 44 years old with a mean age of 26 years. The majority of patients were in the 3rd decade of life. Microscopy shows Breast parenchyma was infiltrated with sheets of neutrophils along with necrosis in the background.

\section{Table 1: Type of benign breast lesions}

\begin{tabular}{|l|l|l|}
\hline \multicolumn{1}{|c|}{ Sr. No. } & \multicolumn{1}{|c|}{ Benign breast lesions } & \multicolumn{1}{c|}{ Percentage } \\
\hline 1. & Fibroadenoma & 60.82 \\
\hline 2. & Fibrocystic disease & 12 \\
\hline 3. & Benign phyllodes tumour & 8.30 \\
\hline 4. & Chronic mastitis & 2.05 \\
\hline 5. & Granulomatous mastitis & 4 \\
\hline 6. & Gynecomastia & 3.6 \\
\hline 7. & Breast abscess & 3 \\
\hline 8. & Other lesions & 6.23 \\
\hline
\end{tabular}

\section{Discussion}

Benign breast diseases encompass a wide range of lesions including inflammatory, neoplastic, and aberrant hormonal response disorders. Increasing awareness of breast cancer, the commonest female malignancy worldwide has stimulated profound interest in benign breast lesions since certain epithelial benign breast lesions have been associated with malignant transformation [8].

Benign breast disease constitutes a heterogeneous group of disorder which is one of the most important causes of breast problems in females and it is more frequent than the malignant ones. Benign breast lesions deserve attention because of their high prevalence, their impact on women's life and the cancerous potential of some histological types [9]. The importance of benign lesions lies in their ability to mimic cancers and not all benign lesions are completely free of risks. Treatment of benign breast disease is the preservation of breast tissue as far as possible in contrast to traumatizing mutilating surgeries in breast cancers. Since a majority of benign lesions are not associated with an increased risk for subsequent breast cancer, unnecessary surgical procedures can be avoided in such lesions [10]. 
The present study was in close relation with Oluwole et al and Ochicha $O$ et al which have been done for 3 years and 5 years. Probably cancerous tissues grow faster and produce more systemic and local manifestations. Hence patient with cancer is brought to the hospital earlier, whereas benign lesions are asymptomatic and slow-growing and so are frequently neglected. Observation made in the present study differed slightly from other authors probably because of the difference in sample size and duration of the study. A profile of breast lesions in Kano showed different rates for female breast disease in different studies but the fibrocystic disease was the most common lesion. The higher incidence of fibrocystic disease in this study may be because more patients with breast diseases now present to hospitals as a result of increased awareness. In the present study the commonest benign breast lesion was fibroadenoma and its variants. In general the vast majority of breast masses in young patients were benign with fibroadenoma accounting for the majority of surgical specimens.

\section{Conclusion}

Breast masses especially in the young age group are a source of anxiety for the patients and surgeons because of the risk of cancer and the potential cosmetic disfigurement following surgery. It has been known for many years that some benign breast lesions are more highly associated with breast cancer than others.

\section{What does the study add to the existing knowledge?}

In the present study various types of benign breast lesions were recorded and the study has shown that benign breast lesions are common and the age incidence of benign breast lesions peaks in the 2nd and 3rd decade.

\section{Author's contributions}

\section{Dr. Bharat Muljibhai Chaudhari: Concept}

Dr. Ashish N Madiya: Manuscript preparation

\section{Reference}

01. Akram M, Iqbal $M$, Daniyal $M$, Khan $A U$. Awareness and current knowledge of breast cancer. Biol Res. 2017;50(1)33.

doi:

$10.1186 / \mathrm{s} 40659-017-0140-9$

[Crossref]
02. Lopez-Garcia MA, Geyer FC, Lacroix-Triki M, Marchió C, Reis-Filho JS. Breast cancer precursors revisited- molecular features and progression pathways. Histopathology. 2010;57(2)171-92.

doi: $10.1111 /$ j.1365-2559.2010.03568.x [Crossref]

03. Geyer FC, Pareja F, Weigelt B, Rakha E, Ellis IO, Schnitt SJ, Reis-Filho JS. The spectrum of triplenegative breast disease- high-and low-grade lesions. Am J Pathol. 2017;187(10)2139-2151. doi: $\quad 10.1016 / j$.ajpath.2017.03.016 [Crossref]

04. Guray M, Sahin AA. Benign breast diseases: classification, diagnosis, and management- The oncologist. 2006;11(5)435-49. doi: 10.

1634/theoncologist.11-5-435 [Crossref]

05. Al-Rikabi A, Husain S. Increasing prevalence of breast cancer among Saudi patients attending a tertiary referral hospital- a retrospective epidemiologic study. Croatian medical journal. $2012 ; 53 ; 239$.

[Crossref]

06. Geetanjali G, Diganta B. Histopathological Spectrum of Breast lesions-A Hospital based study. IJHRMLP. $2016 ; 2 ; 73$.

[Crossref]

07. Singh R, Husen A, Chaudhary A, Maurya R. Clinical profile and management of benign breast disease. Asian Pacific Journal of Health Sciences. 2020;7;81-5.

[Crossref]

08. Ochicha O, Edino S, Mohammed A, Amin S. Benign breast lesions in Kano. Nigerian Journal of Surgical Research. 2002;52(4)211-216. doi: $10.4103 / 0300-1652.93790$ [Crossref]

09. Harrison NA, Kopelman MD, David A, Fleminger S. Endocrine diseases and metabolic disorders, Lishman's Organic Psychiatry. A Textbook of Neuropsychiatry. 2009;617.

[Crossref]

10. Reddy AVM. The spectrum of benign breast lesions-A study in Tertiary Care Hospital. ANNALS OF KING EDWARD MEDICAL UNIVERSITY. 2018;24(1).

doi: 10.21649/akemu.v24i1.2308 [Crossref] 